\title{
The pattern of immunological responses at various stages of syphilis
}

\author{
R. SHANNON AND SUSAN D. BOOTH \\ From the Public Health Laboratory, Kingsdown, Bristol
}

SUMMARY Each of 212 sera, taken from 129 patients with clinically established syphilis, was subjected to seven immunological tests. The tests were designed to detect both anti-lipoidal and antitreponemal antibodies and to titrate antibody of both IgG and IgM molecular species. It was found that patients of similar clinical history were usually recognisable by the similarity of results obtained in the seven tests, and a progression of these patterns of results was also found in samples of serum taken from individual patients during the course of their disease. It is suggested that this more comprehensive type of serological examination of patients can provide valuable information to the clinician.

\section{Introduction}

The appearance and relative abundance of different types of antibody molecule at the various stages of syphilis has already received some attention. In patients with early syphilis anti-lipoidal antibodies occur in the serum fractions sedimenting at $7 \mathrm{~s}$ and 19s. Aho (1967) found that primary cases usually gave higher titres against the 19s fraction, sera from patients with either secondary or early latent syphilis usually showed higher titres against the $7 \mathrm{~s}$ fractions, while those from cases of late syphilis contained mainly 19s antibodies. Julian et al. (1969) reported that in primary cases the Venereal Disease Research Laboratory (VDRL) slide test was sometimes negative for the $19 \mathrm{~s}$ fraction when the corresponding $7 \mathrm{~s}$ sample gave a titre, but never vice versa.

Anti-treponemal globulins include various immunoglobulin classes in cases of primary syphilis (Julian et al., 1969). All but one of 128 cases of untreated syphilis at various stages reported by O'Neill and Nicol (1972) produced both IgM and IgG antibodies. Brown et al. (1970) showed that IgM and IgG antibodies appeared simultaneously in the sera of two of three experimentally infected chimpanzees, whereas IgM appeared first in the other.

In the current study we examined the level of the IgM class antibodies, at the various stages of syphilis, using lipoidal and treponemal antigens.

Address for reprints: R. Shannon, Public Health Laboratory, Myrtle Road, Kingsdown, Bristol BS2 8EL

Received for publication 16 December 1976
These data, together with results of the VDRL slide test and the Treponema pallidum haemagglutination (TPHA) test, were correlated with the clinical diagnosis, to produce an overall view of the course of the immune reactions throughout primary and secondary syphilis.

\section{Materials and methods}

SYPHILITIC SERA

Two hundred and twelve sera from 129 patients at various stages of the disease were selected from specimens taken at routine examinations at the Bristol Public Health Laboratory.

These specimens came mainly from the Bristol Special Clinic and were accompanied by a brief clinical history. No patient with a history of yaws or of latent syphilis was included. The available clinical information was: clinical diagnosis, dates of treatment, and dosage and type of antibiotic. The date of infection was known in very few cases, but the time interval between the last day of treatment and the next sample of serum proved to be a useful datum, which we have called $T_{s}$.

SCREENING OF SERA

Sera were screened routinely by Maltaner cardiolipin complement fixation (CWR) tests, Reiter protein antigen complement fixation (RPCF) tests, VDRL slide tests, and TPHA tests. All sera in this trial were positive in the fluorescent treponemal antibody absorption (FTA-ABS) test. The sera were stored at $-20^{\circ} \mathrm{C}$. 
FRACTIONATION PROCEDURE

Density gradient ultracentrifugations were performed in a 12.5 to $37.5 \%$ discontinuous sucrose gradient (Vesikari and Vaheri, 1968), using $5 \mathrm{ml}$ polycarbonate ultracentrifuge tubes. A sample of serum $(0.4 \mathrm{ml})$ was placed on the top of the sucrose gradient and the tubes were centrifuged at $100000 \mathrm{~g}$ for 18 hours. Ten equal fractions were collected from the bottom by puncturing the tubes with an MSE tube piercer.

An early problem was that some trailing of IgG into the IgM fraction occurred with high titre sera. This was overcome by diluting high VDRL titres to give an equivalent VDRL titre of $1: 2$.

\section{COMPLEMENT FIXATION TESTS}

A six-volume complement fixation test was used; the guinea-pig complement had been titrated in the presence of pooled negative sera and antigen at twice the $50 \%$ haemolytic dose $\left(\mathrm{HD}_{50}\right)$.

Anti-lipoidal antibodies were detected by means of Maltaner cardiolipin antigen (Wellcome Reagents, Ltd).

Anti-treponemal antibodies were detected with Reiter protein antigen (B-D Mérieux. Antigène Tréponémique Souche Reiter).

The working dilutions of the antigens were estimated by a chessboard titration using $2 \mathrm{HD}_{50}$ of complement.

\section{FLUORESCENT TREPONEMAL ANTIBODY}

ABSORBED TEST (FTA-ABS)

The standard technique for FTA-ABS test was carried out (Wilkinson, 1972).

Specific anti-human IgM and IgG conjugates (Wellcome Reagents Ltd) were used in addition to the broad spectrum conjugate of the standard test. Specificity was tested on fractionated sera.

\section{TREPONEMA PALLIDUM}

HAEMAGGLUTINATION TEST (TPHA)

Sera were tested at dilutions of $1: 60$ and $1: 180$ using the microhaemagglutination technique in accordance with the manufacturer's directions (Fjuizoki Pharmaceutical Co. Ltd).

2-MERCAPTOETHANOL TREATMENT (2 ME)

Sera were treated with $0.05 \mathrm{~mol} / 12 \mathrm{ME}$ for $30 \mathrm{~min}$ at $37^{\circ} \mathrm{C}$ to inactivate the IgM globulin. FTA-ABS tests were then carried out on the treated sera (Deutsch and Morton, 1957).

\section{Results}

FRACTIONATION OF SERA

The 10 fractions were examined by agarose gel immunodiffusion against anti-IgM and anti-IgG
(Hyland). A peak found in fractions 3 and 4 was shown to contain only IgM class immunoglobulin and a peak in fractions 7 and 8 contained only the IgG class.

\section{REITER PROTEIN ANTIGEN COMPLEMENT FIXATION TEST}

Each of the fractions from the sucrose gradient centrifugation was titrated by the RPCF test (see Fig. 1). Sixty-nine sera showed fixation with Reiter antigen in both IgM and IgG fractions, 97 sera fixed complement in the IgG fraction only, and three sera fixed complement only in the IgM fraction (these three sera were all from untreated cases of primary syphilis).

Fig. 1 The results of complement fixation and fluorescent treponemal antibody titrations done on a sample of serum after fractionation on a discontinuous sucrose gradient.

\begin{tabular}{lccccccccccc}
\hline \multicolumn{2}{l}{ Sucrose gradient fractions } & & & & & & & \\
& & 1 & 2 & 3 & 4 & 5 & 6 & 7 & 8 & 9 & 10 \\
\hline Maltaner & $2 *$ & 0 & 1 & 4 & 4 & 1 & 0 & 4 & 4 & 1 & 0 \\
cardiolipin & 4 & 0 & 0 & 4 & 4 & 0 & 0 & 4 & 4 & 0 & 0 \\
CFT titre & 8 & 0 & 0 & 2 & 0 & 0 & 0 & 4 & 2 & 0 & 0 \\
& 16 & 0 & 0 & 0 & 0 & 0 & 0 & 0 & 0 & 0 & 0 \\
& 32 & 0 & 0 & 0 & 0 & 0 & 0 & 0 & 0 & 0 & 0
\end{tabular}

\begin{tabular}{lrllllllllll}
\hline Reiter & $2 *$ & 0 & 1 & 4 & 3 & 0 & 1 & 4 & 4 & 0 & 0 \\
protein CFT & 4 & 0 & 0 & 4 & 0 & 0 & 0 & 4 & 4 & 0 & 0 \\
titre & 8 & 0 & 0 & 0 & 0 & 0 & 0 & 4 & 4 & 0 & 0 \\
& 16 & 0 & 0 & 0 & 0 & 0 & 0 & 4 & 2 & 0 & 0 \\
& 32 & 0 & 0 & 0 & 0 & 0 & 0 & 0 & 0 & 0 & 0 \\
\hline
\end{tabular}

\section{FTA IgM}

$++$

$-$

FTA IgG

$-$

$++$

$0=$ complete lysis

$1=25 \%$ cells remaining

$2=50 \%$ cells remaining

$3=75 \%$ cells remaining

$4=100 \%$ cells remaining

*Reciprocal of the dilution

FLUORESCENT TREPONEMAL ANTIBODY

Initially, all 10 fractions from each serum were tested by the FTA-ABS test using specific antihuman IgG and IgM conjugates. The results agreed exactly with those reported above for agarose gel immunodiffusion-that is, fractions 3 and 4 contained IgM class immunoglobulins and fractions 7 and 8 contained the IgG class.

Later, only fractions $3,4,7$, and 8 were tested.

The specificity of the fluorescence was confirmed by treating the fractions with 2-mercaptoethanol. After treatment fractions 3 and 4 failed to fluoresce with anti-human IgM conjugate, whereas fractions 7 and 8 still fluoresced with anti-human IgG conjugate. Eighty-nine sera fluoresced with anti-human IgM conjugate of which 72 also gave positive results to the RPCF test in fractions 3 and 4. 
It is important to note that some batches of antihuman IgM conjugate were contaminated with antihuman IgG conjugate-that is, they showed fluorescence in fractions 7 and 8 . Such batches were rejected.

On comparing the results of the IgM FTA test on the fractionated sera with those obtained from the whole sera, 89 sera were found to be positive in fractions 3 and 4 but only 52 of these were positive when the whole serum was tested. The whole sera giving negative FTA IgM were found mainly in the groups that gave RPCF test titres that were higher in the IgG fractions than in the IgM. This agreed with the finding of Cohen et al. (1967).

\section{LIPOIDAL COMPLEMENT FIXATION TEST}

Each of the fractions was titrated by the CWR test. Eighty-six showed fixation in both IgM and IgG fractions, 112 showed fixation in the IgM fractions alone, and only three showed fixation in the IgG fraction alone. These results were the reverse of the pattern seen in the Reiter protein antigen tests.

\section{VDRL SLIDE TEST}

The VDRL slide test was performed on all sera and the results were compared with the CWR test: 155 sera were positive in both tests, three were positive with the VDRL only, and 52 were positive with the CWR test alone.
TREPONEMA PALLIDUM

HAEMAGGLUTINATION TESTS

TPHA tests were done on all sera: 183 out of 212 were positive. The 29 TPHA negative sera were all from cases of primary syphilis.

\section{INTERPRETATION OF RESULTS}

The results of seven tests were available for each serum-namely (1) CWR test, (a) IgM, (b) IgG; (2) VDRL slide test; (3) RPCF test, (a) IgM, (b) IgG; (4) FTA-ABS IgM; and (5) TPHA. These results are summarised in Table 1 . All sera were positive for FTA-ABS IgG and these results are therefore omitted.

The sera were next sorted into groups corresponding to the 128 possible combinations of the seven results. This yielded the $\mathbf{1 6}$ groups that are shown in Table 1.

\section{Group 1}

This contained all 26 untreated cases of secondary syphilis. The 10 primary cases had had the condition for so long they could be expected immunologically to resemble early secondary cases.

There were also seven cases of treated secondary syphilis but these patients had been treated for only a short time ( $T_{s}=1$ month), and although all the results to tests were positive, the titres were lower.

Table 1 Groups of sera arranged according to the observed combination of test results

\begin{tabular}{|c|c|c|c|c|c|c|c|c|c|c|c|c|}
\hline \multirow{3}{*}{ Group } & \multirow{3}{*}{ Total sera } & \multicolumn{8}{|c|}{ Results of tests } & \multirow{3}{*}{$\begin{array}{l}\text { No. of } \\
\text { sera }\end{array}$} & \multirow{3}{*}{$\begin{array}{l}\text { Clinical } \\
\text { diagnosis }\end{array}$} & \multirow{3}{*}{$T_{s^{*}}$ (months) } \\
\hline & & \multicolumn{2}{|c|}{$C W R$} & \multicolumn{2}{|c|}{$R C P F$} & \multirow[t]{2}{*}{$V D R L$} & \multicolumn{2}{|l|}{$F T A$} & \multirow[t]{2}{*}{$T P H A$} & & & \\
\hline & & $I g M$ & $\overline{I g G}$ & $\operatorname{Ig} M$ & $\overline{I g G}$ & & $I g M$ & $\overline{I g G}$ & & & & \\
\hline 1 & 43 & + & + & + & + & + & + & + & + & $\begin{array}{r}26 \\
7 \\
10\end{array}$ & $\begin{array}{l}\text { Secondary } \\
\text { Secondary } \\
\text { Primary }\end{array}$ & $\begin{array}{r}0 \\
\leqslant 1 \\
0\end{array}$ \\
\hline 2 & 7 & + & + & + & + & + & + & + & - & 7 & Primary & 0 \\
\hline 3 & 9 & + & + & - & + & + & + & + & + & 9 & Secondary & 2 \\
\hline 4 & 27 & + & + & - & + & + & - & + & + & $\begin{array}{r}17 \\
9 \\
1\end{array}$ & $\begin{array}{l}\text { Late } \\
\text { Secondary } \\
\text { Primary }\end{array}$ & $\begin{array}{l}0 \\
2-6 \\
4\end{array}$ \\
\hline 5 & 9 & + & - & + & + & + & + & + & + & $\begin{array}{l}7 \\
2\end{array}$ & $\begin{array}{l}\text { Secondary } \\
\text { Primary }\end{array}$ & $\begin{array}{l}1 \\
0\end{array}$ \\
\hline 6 & 10 & + & - & + & + & + & + & + & - & 10 & Primary & 0 \\
\hline 7 & 3 & + & - & + & - & - & + & + & - & 3 & Primary & 0 \\
\hline 8 & 8 & + & - & - & + & + & + & + & + & $\begin{array}{l}6 \\
2\end{array}$ & $\begin{array}{l}\text { Secondary } \\
\text { Primary }\end{array}$ & $\begin{array}{l}2-4 \\
1\end{array}$ \\
\hline 9 & 33 & + & - & - & + & + & - & + & + & $\begin{array}{r}28 \\
5\end{array}$ & $\begin{array}{l}\text { Secondary } \\
\text { Primary }\end{array}$ & $\begin{array}{l}6-12 \\
1-2\end{array}$ \\
\hline 10 & 14 & + & - & - & + & - & - & + & + & $\begin{array}{l}8 \\
6\end{array}$ & $\begin{array}{l}\text { Secondary } \\
\text { Primary }\end{array}$ & $\begin{array}{r}12-16 \\
6-10\end{array}$ \\
\hline 11 & 28 & + & - & - & - & - & - & + & + & $\begin{array}{r}10 \\
10 \\
8\end{array}$ & $\begin{array}{l}\text { Secondary } \\
\text { Primary } \\
\text { Unknown }\end{array}$ & $\begin{array}{c}12-18 \\
8-12 \\
4-40 \dagger\end{array}$ \\
\hline 12 & 3 & - & + & - & + & + & - & + & + & 3 & Late & 0 \\
\hline 13 & 3 & + & - & - & + & - & - & + & - & 3 & Primary & 7 \\
\hline 14 & 4 & + & - & - & - & - & - & + & - & 4 & Primary & $2-3 \dagger$ \\
\hline 15 & 9 & - & - & - & - & - & - & + & + & 9 & Not known & 14-30t \\
\hline 16 & 2 & - & - & - & - & - & - & + & - & 2 & Primary & 7 and 8 \\
\hline
\end{tabular}

${ }^{*} T_{S}=$ Time interval between treatment and the next sampling of serum $\dagger$ years 


\section{Group 2}

This was characterised by having a negative result in the TPHA test. This result is typically found in early cases of untreated primary syphilis (Sequeira and Eldridge, 1973).

\section{Group 3}

The nine cases of treated secondary syphilis had $T_{s}$ of about two months. The RPCF (IgM) test was negative but the more sensitive FTA (IgM) remained positive. This presumably reflects a reduction in numbers of treponemes after treatment.

\section{Group 4}

This was characterised by the absence of antitreponemal IgM in the presence of IgM and IgG lipoidal antibodies. Sixty-three per cent of the patients $(17 / 27)$ had late syphilis (eight cardivascular syphilis and nine neurosyphilis) and all the rest (one primary and nine secondary cases) had been treated between two and six months before the specimen was taken.

\section{Group 5}

It is likely that in the two untreated primary cases production of lipoidal IgG had not yet begun, whereas its production had ceased in the seven treated cases of secondary syphilis.

\section{Group 6}

A negative TPHA result in conjunction with a positive test for anti-treponemal IgM appears to be typical of cases of untreated primary syphilis. The stage of disease is probably too early for marked production of lipodal antibody.

\section{Group 7}

Here, again, we found a negative TPHA in patients with untreated primary disease, but the negative result for the RPCF test (IgG) indicated that the three cases in this group were probably earlier than those in Group 6.

\section{Group 8}

This contained eight treated cases comprising six patients with secondary syphilis who had $T_{s}=2-4$ months and two primary cases with $T_{s}=1$ month. The results imply that treatment had caused the disappearance of both the anti-lipoidal IgG and RPCF test (IgM) responses, while there was still sufficient antibody production to be detected by the more sensitive FTA (IgM) test.

\section{Group 9}

This contained 33 treated cases comprising 28 patients with secondary syphilis who had a $T_{s}$
$=6-12$ months. The generally long $T_{s}$ is presumably the reason for the disappearance of the FTA (IgM) response.

\section{Group 10}

Here, too, a long $T_{s}$ (eight secondary cases $T_{s}$ 12-16 months and six primary cases $T_{s} 6-10$ months) is likely to account for the disappearance of the VDRL slide test response.

\section{Group 11}

A still longer $T_{s}$ (10 secondary cases $T_{s} \quad 12-18$ months, 10 primary cases $T_{s} 8-12$ months, and eight unknown cases $T_{s}$ 4-40 years) was associated with the negative result to the RPCF test (IgG).

\section{Group 12}

The results of this group are similar to those in Group 4; the negative lipoidal IgM is the only difference. The positive lipoidal IgG with a negative treponemal IgM are seen only in these two groups which contain all the late cases (17 in Group 4 and three in Group 12).

\section{Groups 13 and 14}

These contained seven treated early primary cases with the characteristic negative TPHA. The four cases in Group 14 were RPCF IgG negative.

\section{Group 15}

The nine cases in this group had $T_{s}=14-30$ years. The only positive findings were the TPHA and FTA (IgG).

\section{Group 16}

The two cases of primary syphilis in the group had $T_{s}$ of 7 and 8 months. The only positive result was the FTA (IgG) which indicated that these patients were treated early in the disease before lipoidal antibodies were produced.

Twenty-six patients were regular attenders (5-12 visits) at the clinic and we were able to watch their serum antibodies during the period of treatment and follow-up. The immunological history of one such patient is summarised in Table 2, where it can be seen that his pattern of responses started (with $T_{s}=0$ ) at Group 1, moved through Groups 8 and 9, and arrived at Group 10 when $T_{s}=16$ months.

From a consideration of such histories, we were able to build up a picture of the time course of the typical immune response as reflected by the pattern of reactions and mean titres obtained in the serum tests. Fig. 2(a) graphically illustrates an idealised version of serum antibodies of a case of treated primary syphilis, when treatment began three weeks after infection. Had treatment started earlier-that is, 
Table 2 The immunological history of a treated case of secondary syphilis

\begin{tabular}{|c|c|c|c|c|c|c|c|c|}
\hline \multirow{2}{*}{$T_{S}$ (months) } & \multicolumn{2}{|c|}{$C W R$} & \multicolumn{2}{|c|}{$R P C F$} & \multirow{2}{*}{$V D R L$} & \multirow{2}{*}{$\begin{array}{l}F T A \\
I g M\end{array}$} & \multirow{2}{*}{ TPHA } & \multirow{2}{*}{ Group $\dagger$} \\
\hline & $I g M$ & $I g G$ & $I g M$ & $I g G$ & & & & \\
\hline 0 & $298^{*}$ & 46 & 23 & 59 & 32 & + & + & 1 \\
\hline 1 & 153 & 17 & 2 & 47 & 8 & + & + & 1 \\
\hline 2 & 56 & 0 & 0 & 56 & 8 & + & + & 8 \\
\hline 7 & 17 & 0 & 0 & 27 & 1 & 0 & + & 9 \\
\hline 16 & 8 & 0 & 0 & 26 & 0 & 0 & + & 10 \\
\hline
\end{tabular}

* Reciprocal of the dilution

$T_{S}=$ Time interval between treatment and the next sampling of serum † From Table 1

before the production of lipoidal antibodies-it is likely that the response would have declined rapidly, thus leaving only FTA (IgG) showing a positive reaction (Table 1, Group 16).

In patients with secondary syphilis all of the tests were positive before treatment was given and the immune response declined more slowly than in patients in the primary stage (Fig. 2(b) ).

In none of the cases of late syphilis (eight cardiovascular syphilis, nine neurosyphilis) was there serum that was positive for anti-treponemal IgM in this trial. Group 4 (Table 2) contained 17 of these patients, who had positive reactions for both lipoidal IgG and IgM, whereas the three cases in Group 12 (Table 2) had lipoidal IgG but no lipoidal IgM. The presence of lipoidal IgG without treponemal IgM was characteristic of all the cases of late syphilis that we examined (see Group 4, Table 1). Figure 2c graphically illustrates the idealised immunological history of a case of late syphilis.

\section{Discussion}

The more detailed his knowledge of the time course of immunological responses to a disease, the more confidently can the diagnostician determine the stage of disease and therapeutic state of the patient, and rule out alternative diagnoses. This is particularly true of a disease such as syphilis, whose chronic course combined with the natural reticence of most patients may confuse the clinician. In this study, we have tried to delineate the immunological factors better by using a combination of tests for lipoidaı
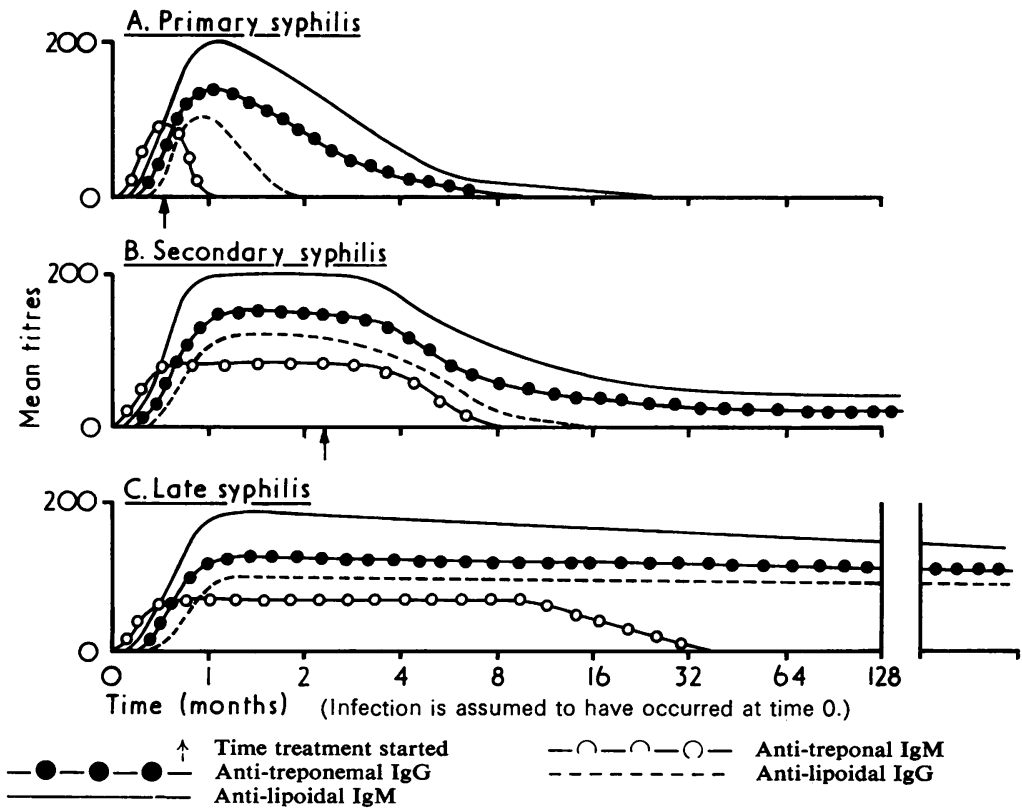

Fig. 2 The time course of immunological responses to syphilis and the influence of treatment. 
and treponemal antigens and by separately assessing the presence of IgG and IgM antibodies to both types of antigen.

The results obtained were generally consistent and pointed strongly to certain conclusions. In a recent study, O'Neill (1976) obtained similar results with fewer tests. In the present study, apart from the 20 cases of late syphilis, the sera that were negative in the tests for treponemal IgM were obtained from patients who had received intensive treatment, either for primary or secondary syphilis. The dosage was usually $1 \cdot 2$ megaunits of penicillin daily for 10 days. In contrast, anti-treponemal IgM was detected in 58 patients who were in the same categories of disease but who had not been treated. There was also a group of 41 patients who had been treated but in whom anti-treponemal IgM was still detectable. These patients had received treatment for a relatively short time before their sera were sampled: 25 had $T_{s}=2$ months and 16 had $T_{s}$ between 2 and 6 months. In groups where both primary and secondary cases were found, the $T_{s}$ for secondary cases was always longer than that of the primary cases. This is presumably because of the large numbers of treponemes in the patient with secondary syphilis and the subsequent delay in their removal by the defence mechanisms.

Moreover, the combination of positive reactions to both anti-lipoidal IgM and anti-treponemal IgG with negative reactions for both anti-lipoidal IgG and anti-treponemal IgM occurred only in successfully treated patients. We suggest that this pattern of results can be taken as a good guide to the success of a course of treatment because it reflects the clearing of treponemes from the body. The persistence of anti-lipoidal IgM supports earlier reports of 19s antibodies in cases of late syphilis (Aho, 1967), and the observations of Julian et al. (1969) on lipoidal antibodies in early syphilis was confirmed in the present study.

The characteristic pattern of the 17 cases of late syphilis in Group 4-namely, persistence of both anti-lipoidal IgM and IgG together with antitreponemal IgG but without anti-treponemal IgM could, perhaps, be due to 'feedback inhibition' of the patients' IgM response in the presence of antitreponemal IgG (Finkelstein and Uhr, 1964). A possibly similar effect was seen by Duncan and Kuhn (1974) in experimentally infected chimpanzees where the production of anti-treponemal IgM antibodies ceased spontaneously in 10 out of 24 untreated animals.

The value of tests for anti-treponemal IgM in diagnosis of untreated or recently treated cases has been well demonstrated; however, the usefulness of the FTA IgM test on whole sera is limited by the large number of false negatives because of competition by IgG molecules for the IgM receptor sites (Cohen et al., 1967).

One patient (Table 1, Group 10) was diagnosed during routine antenatal screening. The tests on this patient showed a pattern typical of a treated case-that is, positive results to anti-lipoidal IgM and anti-treponemal IgG (see Fig. 1). As the patient was known to be allergic to penicillin, it was decided not to start a new course of antibiotic treatment. The baby's serum at birth showed only anti-treponemal IgG since the maternal anti-lipoidal IgM had, presumably, failed to cross the placenta. Three months later, the baby's serum was negative.

It is obviously desirable that the present study should be extended, in particular, to investigate the possible patterns caused by congenital syphilis and to evaluate the clinical entity of latent syphilis. However, the results obtained so far clearly help to place the patient in a broad category and to reinforce the clinical diagnosis.

We are indebted to Dr H. R. Cayton, Director of the Bristol Public Health Laboratory, for granting permission and facilities to carry out this work and for helpful advice and criticism. We are also grateful to Dr A. E. Tinkler, Dr A. L. Hilton, and Dr G Morrison and their staff for help with the clinical data.

\section{References}

Aho, K. (1967). Studies of syphilitic antibodies. I. Anti-lipoidat antibodies in various stages of syphilis. British Journal of Venerea Diseases, 43, 259-263.

Brown, W. J., Kuhn, U. S. G., Tolliver, E. A., and Norins, L. C. (1970). Experimental syphilis in the chimpanzee. Immunoglobulin class of early antibodies reactive with Treponema pallidum. British Journal of Venereal Diseases, 46, 198-200.

Cohen, I. R., Norins, L. C., and Julian, A. J. (1967). Competition between, and effectiveness of, IgG and IgM antibodies in indirect fluorescent antibody and other tests. Journal of Immunology, 98 143-149.

Deutsch, H. F., and Morton, J. I. (1957). Dissociation of human serum macroglobulins. Science, 125, 600-601.

Duncan, W. P., and Kuhn, U. S. G. (1974). Treponemal IgG and IgM responses in experimentally infected chimpanzees. British Journal of Venereal Diseases, 50, 257-263.

Finkelstein, M. R., and Uhr, J. W. (1964). Specific inhibition of antibody formation by passively administered $19 \mathrm{~s}$ and $7 \mathrm{~s}$ antibody. Science, 146, 67-69.

Julian, A. J., Logan, L. C., and Norins, L. C. (1969). Early syphilis: Immunoglobulins reactive in immunofluorescence and other serologic tests. Journal of Immunology, 102, 1250-1259.

O'Neill, P. (1976). A new look at the serology of treponemal disease. British Journal of Venereal Diseases, 52, 296-299.

O'Neill, P., and Nicol, C. S. (1972). IgM class antitreponemal antibody in treated and untreated syphilis. British Journal of Venereal Diseases, 48, 460-463.

Sequeira, P. J. L., and Eldridge, A. E. (1973). Treponemal haemag glutination test. British Journal of Venereal Diseases, 49, 242-248.

Vesikari, T., and Vaheri, A. (1968). Rubella: A method for rapid diagnosis of a recent infection by demonstration of the IgM antibodies. British Medical Journal, 1, 221-223.

Wilkinson, A. E. (1972). Laboratory Diagnosis of Venereal Disease. Monograph Series No. 1, pp. 18-24. Public Health Laboratory Service: London. 